\section{Spheres of}

\section{Transformation}

Jenna Nemec-Loise

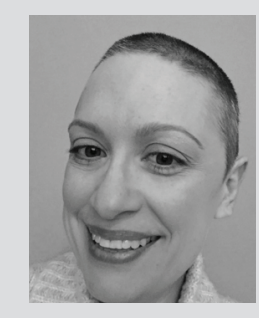

Jenna Nemec-Loise is Member Content Editor, ALSC EVeryday Advocacy website and electronic newsletter.
Everyday Advocacy empowers ALSC members to embrace their roles as library advocates by focusing on their daily efforts to serve kids and families. Each lighthearted column features easy-to-implement strategies and techniques for asserting the transformative power of libraries both within communities and beyond them. Please contact Jenna Nemec-Loise at jnemecloise@outlook .com with comments and ideas for future topics.

$\mathrm{E}$ eeeeee! Who's excited about the 2017-20 ALSC strategic plan? (Insert cartwheel here.) If you're even a fraction of the organizational governance nerd I am, I'll bet you're 100 percent jazzed, too.

Haven't checked out the plan yet? Stop whatever you're doing right now and have a look. (Find the plan at www.ala.org/alsc/aboutalsc/stratplan.) I promise it won't take long to get a strong sense of where ALSC hopes to be just three short years from now.

There's a lot to love here, right?

First off, the plan's visual appeal is awesome. The infographic shows, rather than tells, members, stakeholders, and outsiders what ALSC is all about. At a glance you can tell what's important for the next three years and how it relates to the larger ALSC picture.

Next is the plan's member-focused and member-driven content. During every stage of the strategic planning process, the ALSC board of directors didn't stop at listening to respond to members. Our leaders went the distance and listened to understand them, which resulted in clear, no-nonsense approaches to the plan's three areas of strategic action: Diversity and Inclusion, Advocacy (yay!), and Learning and Development.

\section{Spheres of Transformation}

Perhaps the depth, breadth, and reach of the new strategic plan is

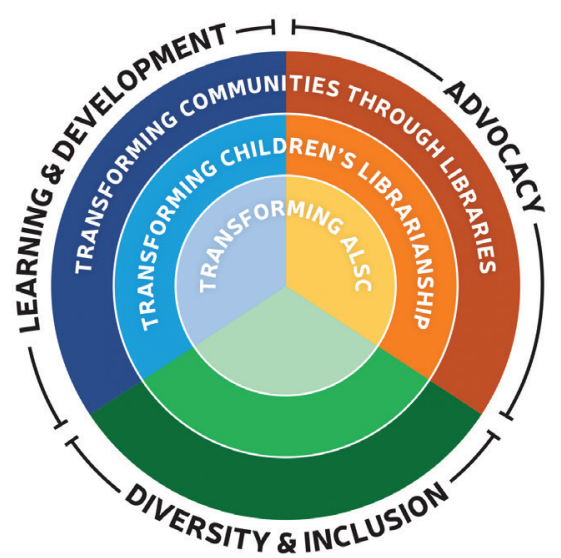
best captured through the plan's three concentric spheres of transformation, each of which reflects ALSC's core values and the division's fierce commitment to empowering membership:

- Transforming ALSC. Members have clear, welcoming pathways to contribute to the work of the association;

- Transforming Children's Librarianship. ALSC empowers the profession to be nimble and embrace change as children's needs evolve; and 
- Transforming Communities through Libraries. ALSC and libraries are essential partners in a comprehensive system of care for children.

As we dig deeper into the strategic plan's Advocacy objectivesthis is the Everyday Advocacy column, after all-consider your role in each sphere of transformation. Think beyond the three organizational spheres and ask yourself, "What are my own spheres of transformation?" Keep these questions in mind:

- Transforming My Library. How do I contribute to the work of my library beyond essential job responsibilities?

- Transforming My Role as Everyday Advocate. How do I embrace change and honor the evolving needs of my library's children and families through my work?

- Transforming My Library Community. How do I amplify my library's role as a community partner and ally in improving outcomes for the children and families?

Recognizing your role as a prime mover and change agent within the larger ALSC strategic plan is Everyday Advocacy in action!

\section{Advocacy as Area of Strategic Action}

For the 2017-2020 strategic plan period, ALSC is placing greater emphasis on helping members champion and articulate the purpose and value of strong and meaningful library service to children. Here are the four objectives outlined under the Advocacy area of strategic action and related questions for your consideration as an Everyday Advocate:

1. Establish an accessible content stream of valuation tools and research updates, including customizable content for members, by September 2018. (Transforming ALSC)

Questions for Everyday Advocates: What valuation tools would be most useful in my library community? Where do I see a need for greater valuation efforts? Which programs or services I currently provide would benefit from greater advocacy and valuation efforts?

2. Articulate a prioritized research agenda, including, but not limited to, summer learning/out-of-school time, by September 2018, and pursue avenues for conducting and/or supporting the research by September 2020. (Transforming Children's Librarianship)

Questions for Everyday Advocates: What research topics would I most like to see ALSC pursue? What areas of my work as an Everyday Advocate would be bolstered with research and data? What expertise and evidence-based practice can I share with ALSC as the research agenda is being formulated?

3. Amplify librarians' essential role as information literacy experts through advocacy outputs, including communications, webinars, and establishing collaborations, by September 2018. (Transforming Communities through Libraries)

Questions for Everyday Advocates: How am I currently asserting my role as an information literacy expert? What skills can I cultivate to do so more effectively? What types of professional development opportunities would help me achieve greater competency in this area?

4. Increase targeted messaging to the wider library profession and the public about the expertise of ALSC and our members to demonstrate the purpose and value of strong and meaningful children's librarianship by September 2019. (Transforming Communities through Libraries)

Questions for Everyday Advocates: What audiences have I already reached successfully with such messaging? Which groups can I target at local and state levels? Who in my circle of advocates can help me identify multiple communication channels and disseminate messaging?

\section{Getting Involved}

As ALSC leadership activates members to enact the 2017-2020 strategic plan, we're counting on Everyday Advocates like you to lead the way! Let ALSC President Nina Lindsay or any member of the ALSC board of directors know how you'd like to contribute. Keep us posted on what's happening in your library community and how the strategic plan's spheres of transformation and areas of strategic action are impacting your work.

Really want to dig in? Submit the all-new electronic version of the ALSC Committee Volunteer Form (find it at www.ala.org /alsc/aboutalsc/coms/alscforms) and indicate your interest in Priority Group I: Child Advocacy. The work of our dynamic committees will be guided and shaped by the objectives outlined in the Diversity and Inclusion, Advocacy, and Learning and Development areas of strategic action. Committees can't do this awesome work without you!

Finally, tools and resources on the Everyday Advocacy website (www.ala.org/everyday-advocacy) will evolve to reflect the new strategic plan as the work of ALSC moves forward. Keep checking back to find all the support you need to succeed in your own spheres of transformation, which are powerful indeed. $\delta$ 